\title{
Aggregation Behavior of Polybenzimidazole in Aprotic Polar Solvent
}

Arindam Sannigrahi, Dhamodaran Arunbabu, R. Murali Sankar and

\author{
Tushar Jana* \\ School of Chemistry \\ University of Hyderabad \\ Hyderabad, India \\ Tel: (91) 4023134808 \\ Fax: (91) 4023012460 \\ E-mail: tjsc@uohyd.ernet.in \\ (* To whom correspondence should be addressed) \\ Supporting Information
}




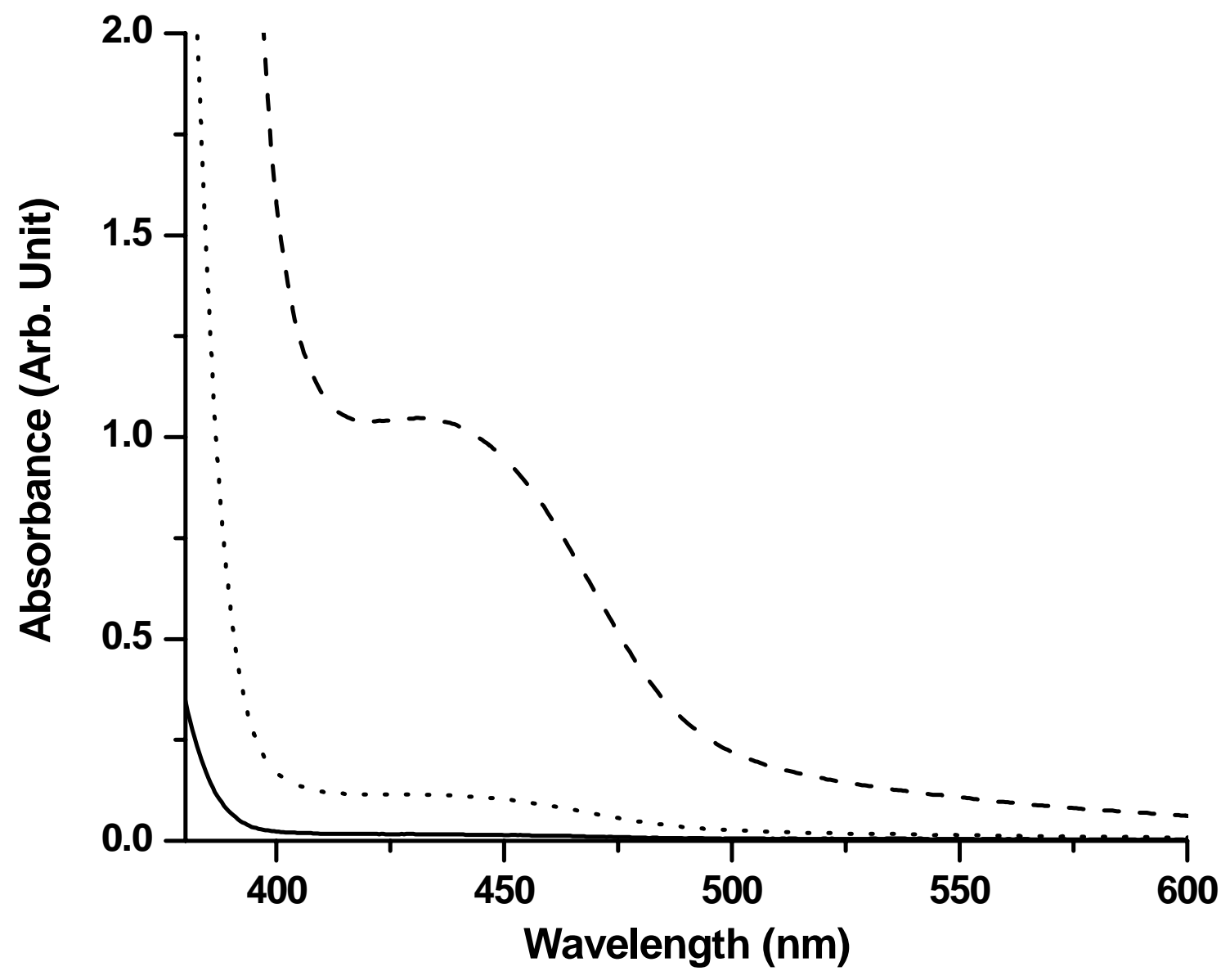

Supp. Figure 1: Absorption spectra of PBI in DMAc solution at various concentrations; (- - -) $1.54 \times$ $\left.10^{-1} \mathrm{~g} / \mathrm{dl},(----)\right) 1.54 \times 10^{-2} \mathrm{~g} / \mathrm{dl}$ and (-) $1.54 \times 10^{-3} \mathrm{~g} / \mathrm{dl}$ 


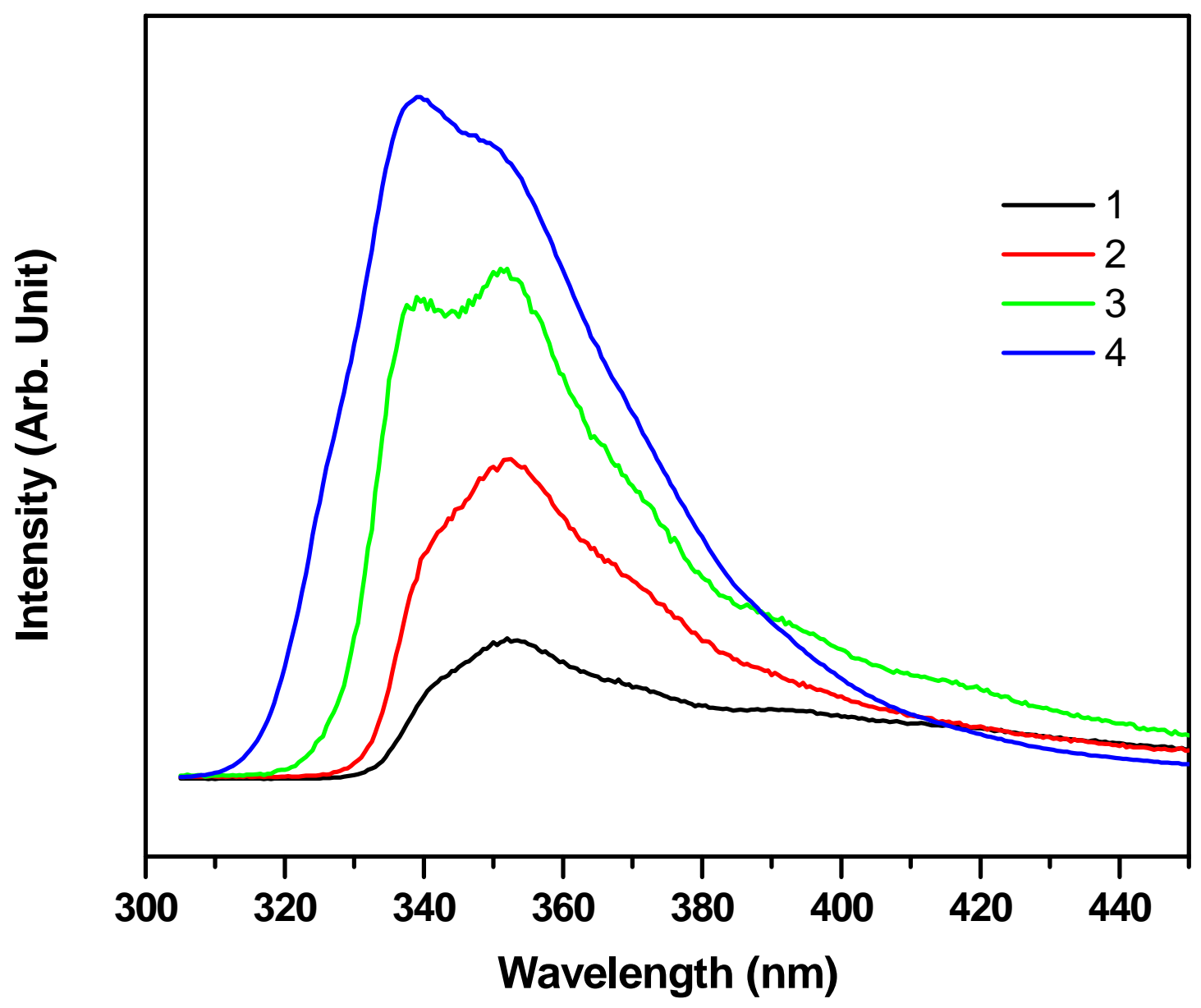

Supp. Figure 2: Fluorescence emission spectra of BBI in DMAc solution at various concentrations; (1) $1.5 \times 10^{-1} \mathrm{~g} / \mathrm{dl},(2) 1.17 \times 10^{-1} \mathrm{~g} / \mathrm{dl},(3) 1.17 \times 10^{-2} \mathrm{~g} / \mathrm{dl}$ and (4) $1.17 \times 10^{-3} \mathrm{~g} / \mathrm{dl}$. Excitation wavelength $\left(\lambda_{\text {exc }}\right)$ is $295 \mathrm{~nm}$. 

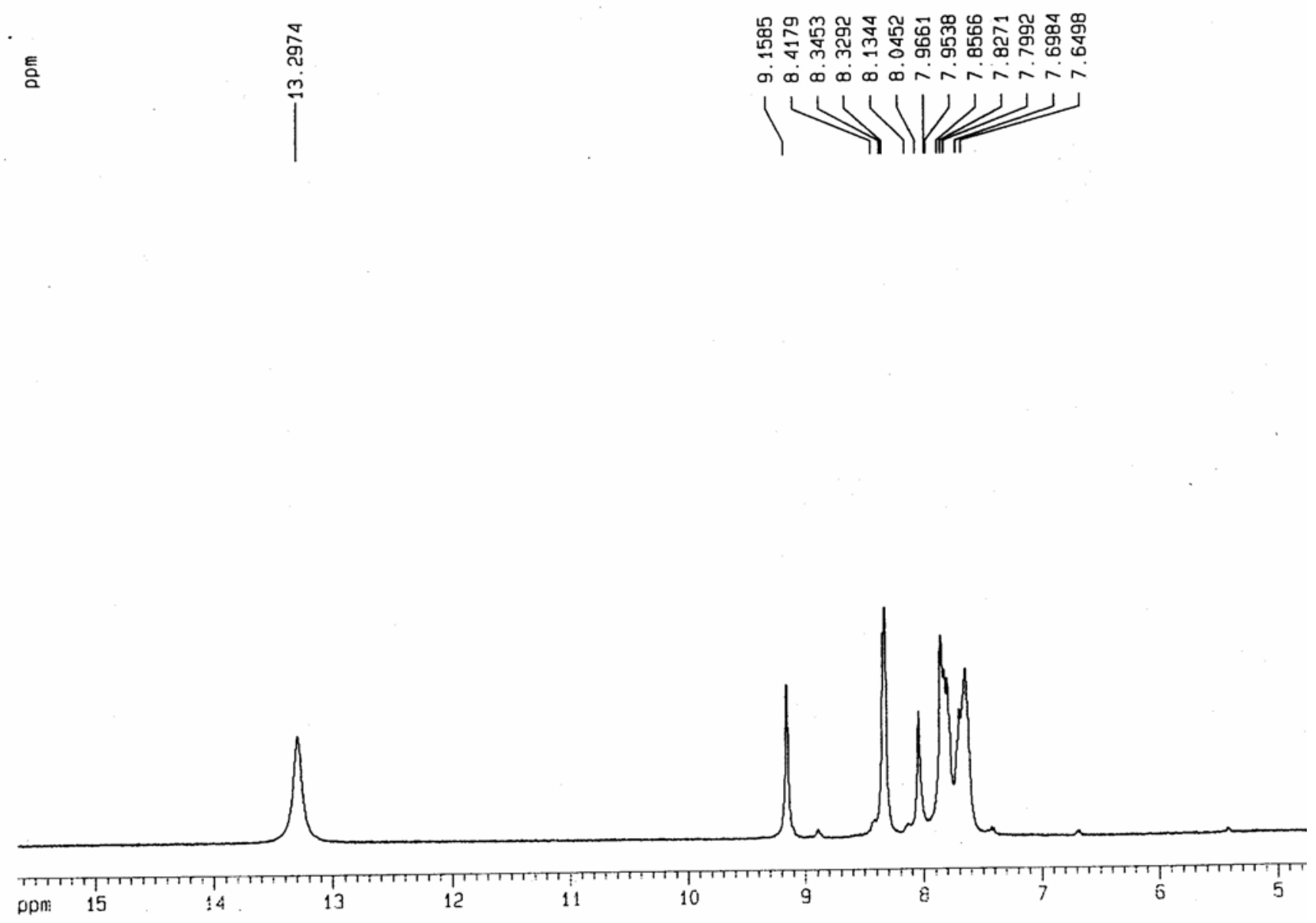

Supp. Figure 3: Proton NMR spectrum of PBI in DMSO $-\mathrm{d}_{6}$. 


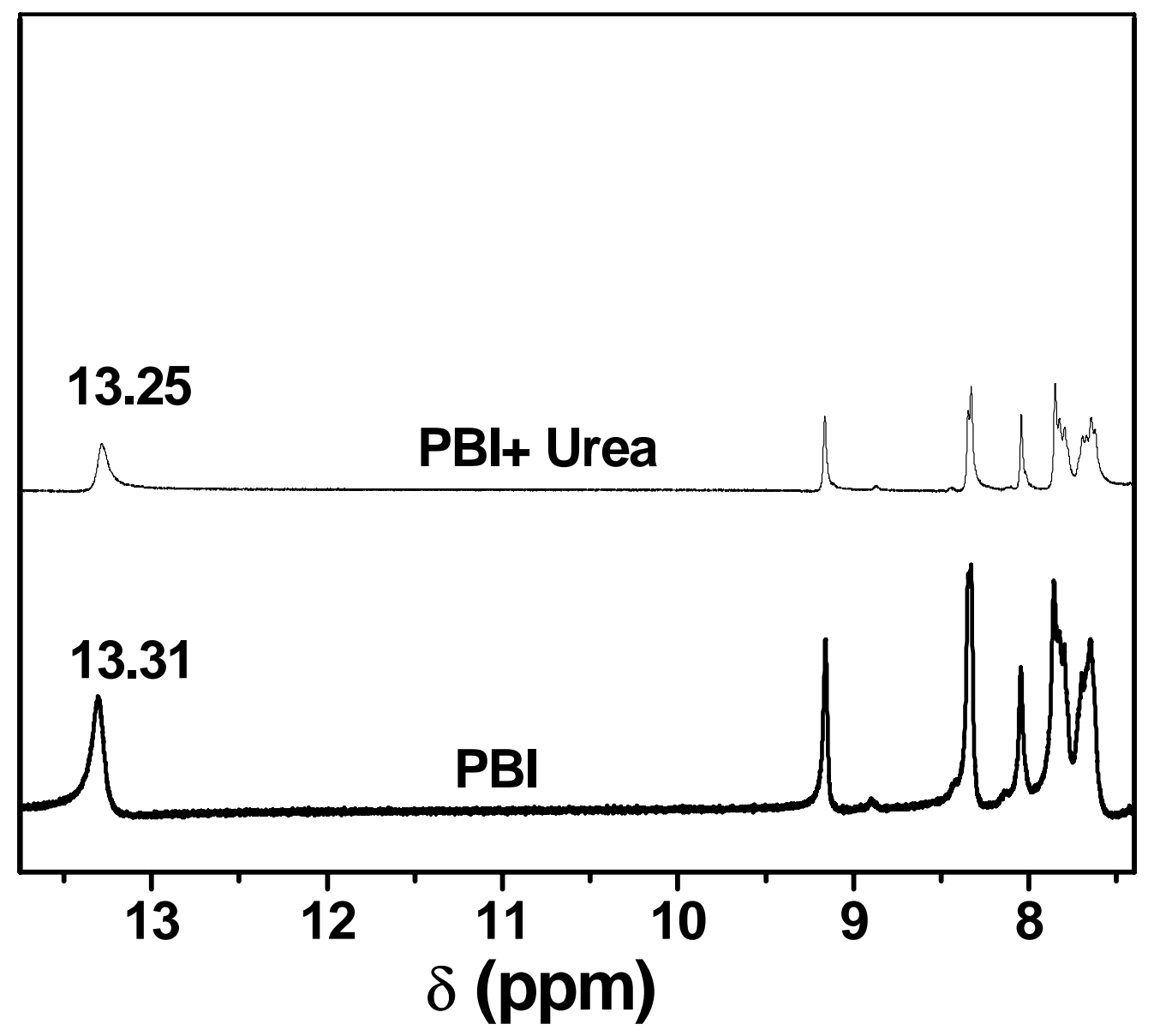

Supp. Figure 4: Upfield shift and reduced intensity of imino proton signal in presence of urea. Note that other signals have not changed. 